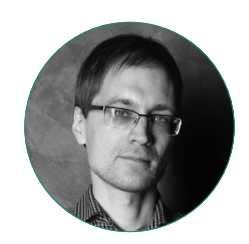

Д. М. Логинов

\title{
СОЦИАЛЬНОЕ САМОЧУВСТВИЕ РОССИЙСКОГО НАСЕЛЕНИЯ В ПЕРИОД ОСТРОЙ ФАЗЫ ЭПИДЕМИОЛОГИЧЕСКОГО КРИЗИСА
}

\section{Правильная ссылка на статью:}

Логинов Д. М. Социальное самочувствие российского населения в период острой фазы эпидемиологического кризиса // Мониторинг общественного мнения: экономические и социальные перемены. 2020. № 6. С. 470-487. https://doi.org/10.14515/monitoring. 2020.6.1708.

\section{For citation:}

Loginov D. M. (2020) Social Well-Being of the Russian Population During the Acute Stage of the Epidemiological Crisis. Monitoring of Public Opinion: Economic and Social Changes. No. 6. P. 470-487. https://doi.org/10.14515/monitoring.2020.6.1708. (In Russ.) 
СОЦИАЛЬНОЕ САМОЧУВСТВИЕ РОССИЙСКОГО НАСЕЛЕНИЯ В ПЕРИОД ОСТРОЙ ФАЗЫ ЭПИДЕМИОЛОГИЧЕСКОГО КРИЗИСА

лОГИНОВ Дмитрий Михайлович - кандидат экономических наук, старший научный сотрудник Института социального анализа и прогнозирования, Российская академия народного хозяйства и государственной службы при Президенте РФ, Москва, Россия E-MAIL: loginov-dm@ranepa.ru https://orcid.org/0000-0002-2717-6909

Аннотация. На основе данных социологического опроса, проведенного Институтом социального анализа и прогнозирования РАНХиГС $(N=3500)$ в апреле 2020 г., рассмотрены показатели социального самочувствия россиян в период острой фазы эпидемиологического кризиса. Показано, что большая часть населения серьезно восприняла эпидемиологическую угрозу распространения COVID-19 и скорректировала собственное поведение с целью минимизации соответствующих рисков. Типология самоограничительного поведения иллюстрирует наличие двух массовых групп, представители которых характеризуются высоким уровнем самоограничений (высокий уровень самоограничений при значительных эпидемиологических опасениях, высокий уровень самоограничений при отсутствии значительных эпидемиологических опасений). Выявлены риски в сферах доходов и занятости, связанные с ухудшением материального положения граждан и их опасениями потерять работу. Обнаружено, что, основываясь на опыте адаптации к прошедшим периодам экономической нестабильности, значительные группы
SOCIAL WELL-BEING OF THE RUSSIAN POPULATION DURING THE ACUTE STAGE OF THE EPIDEMIOLOGICAL CRISIS

Dmitry M. LOGINOV ${ }^{1}$ - Cand. Sci. (Econ.), Senior Researcher at the Institute for Social Analysis and Forecasting E-MAIL: loginov-dm@ranepa.ru https://orcid.org/0000-0002-2717-6909

\footnotetext{
${ }^{1}$ Russian Presidential Academy of National and Public Administration, Moscow, Russia
}

Abstract. Based on the data of a survey conducted by the Institute for Social Analysis and Forecasting (RANEPA) in April 2020 the article considers the Russians' well-being indicators during the acute stage of the epidemiological crisis $(N=3,500)$. The study shows that most of the population perceived the threat of COVID-19 epidemic and adjusted their own behaviors to minimize potential risks. According to the types of self-limiting behaviors two large groups were detected, each with high prevalence of self-restrains. The article explores the risks related to income and employment, the worsening of individual's financial situation and individuals' fears of losing the job. Based on the previous experiences of adaptation to the periods of econom ic instability, large groups of populations intend to adopt a number of adaptation strategies which include lower consumer activities coupled with efforts to find an additional source of income or a side job. The results suggest that there is a mismatch in terms of respondents' approvals of the government decisions: respondents consider the measures aiming to tackle the epidemiological situation to be quite adequate, however 
населения предполагают реализовать комплекс адаптационных практик, в число которых входят как снижение потребительской активности, так и активизация усилий на рынке труда, выражающихся в поиске дополнительной работы и приработков.

По результатам исследования наблюдается существенная асимметрия в уровне одобрения респондентами властных управленческих решений: меры, направленные на стабилизацию эпидемиологической обстановки, респонденты считают адекватными, а уровень социальной поддержки населения представляется им недостаточным, следовательно, запрос на расширение социальной поддержки в обществе крайне высок.

Ключевые слова: социальное самочувствие, уровень жизни, социально-экономическое поведение, социально-экономическая адаптация, коронавирус , COVID-19

Благодарность. Статья подготовлена в рамках выполнения научно-исследовательской работы государственного задания РАНХиГС. they think that the level of social support is not sufficient, therefore, more efforts to improve social assistance are needed.
Keywords: social well-being, socio-economic behaviour, socio-economic adaptation, coronavirus , COVID-19, living standards

Acknowledgments. The article is part of the research work under the state assignment to RANEPA.

Ситуация, вызванная распространением новой коронавирусной инфекции и реализацией мер противодействия ей весной 2020 г., актуализировала существенные изменения в жизнедеятельности и экономической активности массовых групп российского общества. Сложившиеся социально-экономические условия характеризуются рядом важных особенностей. Во-первых, это "острота момента", поскольку необходимость изменений жизнедеятельности обострилась в течение краткого временно́го периода. Во-вторых, вынужденными корректировками оказались затронуты все аспекты жизнедеятельности: принципиально изменились параметры занятости и условия осуществления предпринимательской деятельности, возможности поддержания стиля жизни, коммуникационные практики и т. п. В-третьих, ситуация нестабильности возникла на исходе не самого благополучного пятилетия, в течение которого массовые социальные группы, столкнувшись с па- 
дением доходов, исчерпали значительную часть имевшегося "запаса прочности", выстраивая практики адаптации к новой реальности второй половины 2010-х годов. И, наконец, новая кризисная ситуация актуализировалась в контрвекторе социальных ожиданий, когда население, в значительной мере адаптировавшись к падению доходов предшествовавшего периода, к концу 2019 г. сформировало ожидания дальнейшей стабилизации и роста благосостояния.

Особенности восприятия различными группами населения макросоциальных перемен и реализуемые на основе этого восприятия поведенческие модели рассматривались в рамках адаптационного дискурса 1990-х годов [Гордон, 1994; Заславская, 1995; Тихонова, 1997; Авраамова, Логинов, 2002]. На фоне экономической стагнации и снижения доходов населения исследования адаптационных практик были актуализированы во второй половине 2010-х годов [Авраамова, Логинов, 2015; Тихонова, Каравай, 2016]. Объемная и комплексная рефлексия последствий разворачивающегося кризиса еще впереди, но уже сейчас очевидна глубина и многогранность вызванных им социально-экономических проблем [Колодко, 2020; Григорьев, Павлюшина, Музыченко, 2020], а также необходимость адекватных комплексных решений, направленных на преодоление его последствий [Полбин, Синельников-Мурылев, Трунин, 2020; Анпилов, Сорочайкин, 2020; щетинина, 2020]. Оперативный мониторинг складывающейся ситуации подтверждает шоковый характер произошедших изменений и ситуативность адаптационных практик различных социальных групп [Мониторинг мнений..., 2020а; Мониторинг мнений..., 2020б; Аналитический бюллетень..., 2020].

В середине апреля текущего года Институтом социального анализа и прогнозирования РАНХиГС реализован массовый анкетный опрос (3500 респондентов) по репрезентативной для населения России в возрасте 18-65 лет выборке. Результаты позволяют выявить оценки, ожидания и представления различных групп населения страны о складывающемся социально-экономическом контексте и перспективах его изменения в условиях острой фазы эпидемиологического кризиса весной 2020 года ${ }^{1}$.

Актуальность данного исследования определяется не только эксклюзивностью социально-экономического контекста по отношению к предшествующим периодам, но и неопределенностью дальнейшего развития ситуации, что делает особенно важным рефлексию накопленного социального опыта.

\section{Восприятие ситуации и актуализация самоограничений}

Около половины опрошенных россиян в апреле 2020 г. назвали ситуацию с распространением новой коронавирусной инфекции в пункте своего проживания серьезной (в том числе $13 \%$ - очень серьезной). Чуть более трети опрошенных

\footnotetext{
1 Выборка для опроса, проведенного методом телефонного интервью,-случайная систематическая стратифицированная; номера телефонов сгенерированы на основе задействованных DEF диапазонов на территории России, по информации с официального сайта Россвязи по состоянию на 1 января 2020 г.). Диапазоны позволили таргетировать телефонные номера до субъектов РФ для создания территориальных страт. Распределение выборки по стратам рассчитано на основе данных Росстата о численности населения, проживающего на территории выделенных страт, на 1 января 2020 г. Для массива данных рассчитан вес, выравнивающий половозрастную структуру (по информации Росстата). Статистическая погрешность данных исследования при использованном дизайне выборки не превышает $2 \%$. База данных по результатам опроса будет размещена на Портале социологических данных РАНХиГС. Подробнее см.: https://social.ranepa.ru/ (дата обращения: 15.12.2020).
} 
не имели существенных опасений, а каждый восьмой респондент зафиксировал представления об абсолютной незначимости угрозы.

Особенности формирования выборочной совокупности не позволяют выявить региональную специфику, которая, безусловно, важна вследствие ассиметричных изменений эпидемиологической обстановки. Однако мы имеем возможность рассмотреть территориально-поселенческий аспект остроты восприятия коронавирусной угрозы. Данные, представленные на рисунке 1, показывают, что чем крупнее населенный пункт, тем в большей степени его жители были склонны высказывать опасения. В городах-миллионниках угроза представлялась очень серьезной каждому четвертому, тогда как в прочих городских и сельских поселениях такого мнения придерживались $7 \%-12 \%$ опрошенных. Суммируя группы респондентов, представители которых рассматривали угрозу как серьезную, можно констатировать почти двукратные различия между мегаполисами, жители которых были склонны к наиболее алармистским настроениям, и сельскими жителями, воспринимавшими ситуацию максимально спокойно. Показатели малых городов в большей степени приближены к показателям, отмеченным в сельских территориях.

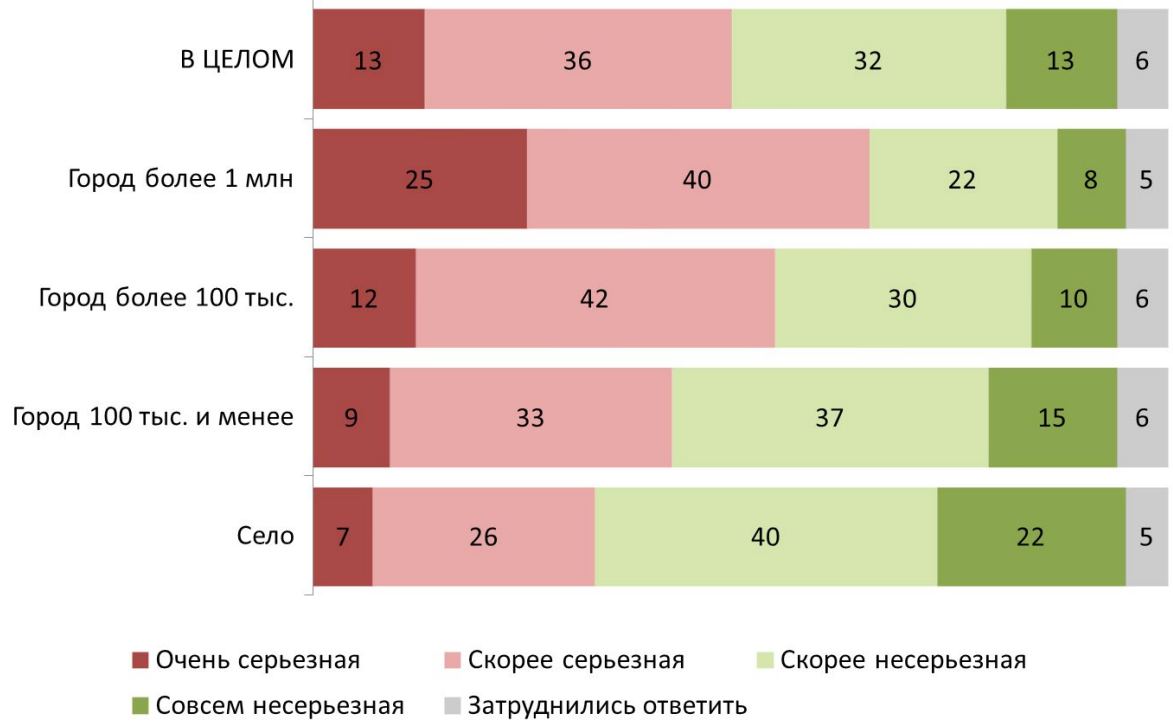

Рис. 1. Оценка угрозы распространения COVID-19, по типам поселений (\%)

Большинство опрошенных (67\%) сообщили, что соблюдали режим самоизоляции и социального дистанцирования (кроме необходимых и разрешенных в момент опроса действий, связанных с работой, покупкой продуктов и выгулом домашних животных), и лишь 4 \% респондентов не предпринимали никаких самоограничительных мер. Важно отметить, что такое поведение очень быстро стало социальной нормой, характеризуя различные поселенческие и возрастные группы в практически равной степени (см. рис. 2). 


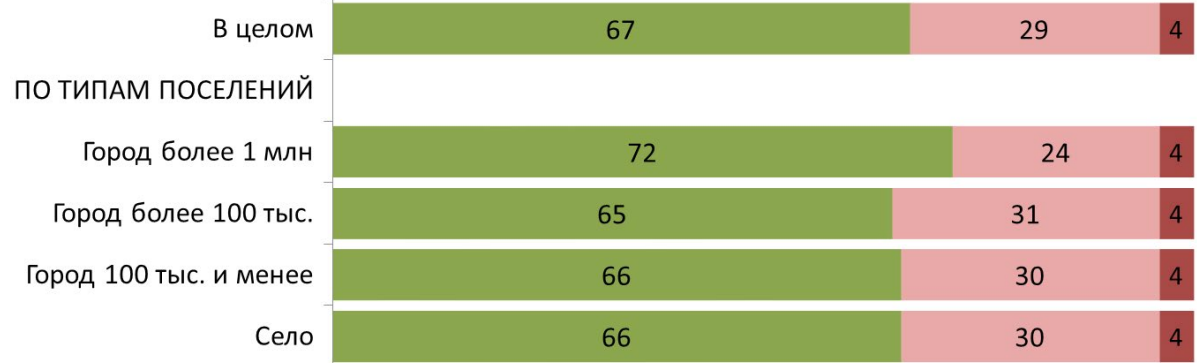

ПО ВОЗРАСТАM

\begin{tabular}{r|ccc|}
\hline 18-34 года & 68 & 28 & 4 \\
\hline $35-54$ года & 66 & 30 & 4 \\
\hline 55 лет и старше & 69 & 28 & 3 \\
\hline
\end{tabular}

п Соблюдаю полностью шоблюдаю частично

Рис. 2. Соблюдение режима самоограничений, по типам поселений и возрастным группам (\%)

На основе комбинирования информации о восприятии респондентами уровня эпидемиологической угрозы и соблюдении ими мер социальной изоляции реализована типология самоограничительного поведения населения, с учетом остроты восприятия эпидемиологической угрозы. Выделяются следующие группы:

1. Высокий уровень самоограничений при значительных эпидемиологических опасениях, что предполагает оценку угрозы распространения вируса как очень или скорее серьезную и максимальное соблюдение режима самоизоляции - $36 \%$;

2. Отсутствие высокого уровня самоограничений при значительных эпидемиологических опасениях, когда риски представляются серьезными, но максимальный самоизоляционный режим отсутствует - $13 \%$;

3. Высокий уровень самоограничений при отсутствии значительных эпидемиологических опасений, то есть соблюдение максимального самоизоляционного режима при оценке вирусной угрозы как незначительной - $32 \%$;

4. Отсутствие высокого уровня самоограничений при отсутствии значительных эпидемиологических опасений. В данную группу включены те, кто не придерживается максимального самоизоляционного режима на фоне восприятия соответствующих рисков несерьезными - 19\%.

Реализованная типология показывает, что около $55 \%$ населения продемонстрировали полное соответствие поведенческих практик своим представлениям об остроте эпидемиологической угрозы. В отношении остальных существует явный (и очевидно позитивный) дисбаланс: существенно чаще несовпадение характеризуется ограничениями в субъективно не очень опасной внешней среде, чем наоборот - когда за восприятием рисков не следуют ограничительные практики.

Рассмотрим социально-демографическую дифференциацию выделенных поведенческих типов. 
Как показывают результаты, представленные в таблице 1, поселенческие различия крайне значительны, и в наибольшей мере выделяются жители мегаполисов. Ровно половина из проживающих в крупных городах относится к первому поведенческому типу, демонстрируя самосохранительное поведение на фоне серьезного восприятия существующих рисков. По мере снижения размера населенного пункта актуализация такого поведения снижается, доходя до $23 \%$ в сельских поселениях. Наименее подвержен влиянию поселенческого фактора поведенческий паттерн, который предполагает игнорирование рисков. Поскольку сельские жители, как было рассмотрено выше, считали ситуацию наименее опасной, среди них очевидным образом максимально распространены третий и четвертый поведенческие типы, при этом особенности стиля жизни позволили самой массовой группе селян соблюдать осторожность, даже когда это не представлялось им необходимым.

Таблица 1. Типология ограничительного поведения

с учетом остроты восприятия угрозы, по типам поселений (\% по строке)

\begin{tabular}{|c|c|c|c|c|}
\hline \multirow[b]{2}{*}{ Типы поселения } & \multicolumn{4}{|c|}{ Типы поведения } \\
\hline & $\begin{array}{c}\text { Существенные } \\
\text { ограничения при } \\
\text { значительных } \\
\text { опасениях }\end{array}$ & $\begin{array}{c}\text { Отсутствие } \\
\text { существенных } \\
\text { ограничений при } \\
\text { значительных } \\
\text { опасениях }\end{array}$ & $\begin{array}{c}\text { Существенные } \\
\text { ограничения } \\
\text { при отсутствии } \\
\text { значительных } \\
\text { опасений }\end{array}$ & $\begin{array}{c}\text { Отсутствие } \\
\text { существенных } \\
\text { ограничений } \\
\text { при отсутствии } \\
\text { значительных } \\
\text { опасений }\end{array}$ \\
\hline $\begin{array}{l}\text { Города более } \\
1 \text { млн жителей }\end{array}$ & 50 & 15 & 22 & 13 \\
\hline $\begin{array}{l}\text { Города более } \\
100 \text { тыс. жителей }\end{array}$ & 39 & 15 & 26 & 20 \\
\hline $\begin{array}{l}\text { Города } \\
\text { до } 100 \text { тыс. жителей }\end{array}$ & 30 & 12 & 37 & 21 \\
\hline Сельские поселения & 23 & 10 & 43 & 24 \\
\hline В целом & 36 & 13 & 32 & 19 \\
\hline
\end{tabular}

Возрастные различия (см. табл. 2) проявляются прежде всего в том, что самые молодые респонденты несколько чаще демонстрировали ограничительное поведение на основе актуализации значительных рисков, а представители старшей когорты больше представлены в числе тех, кто принял на себя ограничения, не будучи уверенными в их объективной необходимости.

Поскольку уровень образования традиционно рассматривается в числе параметров, влияющих как на восприятие окружающего контекста, так и на формирование моделей социального поведения, представляется небезынтересным выяснить, как меняется наполненность выделенных групп в зависимости от имеющегося образовательного потенциала. Из данных, приведенных в таблице 3, видно, что наличие высшего образования является фактором, принципиально дифференцирующим остроту восприятия эпидемиологической угрозы и формируемые на основе этого поведенческие практики. Различия между имеющими среднее профессиональное образование и вообще не получившими профессиональной подготовки существенно менее выражены (4-8\%). 
Таблица 2. Типология ограничительного поведения с учетом остроты восприятия угрозы, по возрастным группам (\% по строке)

\begin{tabular}{|l|c|c|c|c|}
\hline \multirow{2}{*}{$\begin{array}{c}\text { Возрастные } \\
\text { группы, лет }\end{array}$} & $\begin{array}{c}\text { Существенные } \\
\text { ограничения при } \\
\text { значительных } \\
\text { опасениях }\end{array}$ & $\begin{array}{c}\text { Типы поведения } \\
\text { отсутствие } \\
\text { существенных } \\
\text { значительных } \\
\text { опасениях }\end{array}$ & $\begin{array}{c}\text { Существенные } \\
\text { ограничения } \\
\text { при отсутствии } \\
\text { значительных } \\
\text { опасений }\end{array}$ & $\begin{array}{c}\text { Отсутствие } \\
\text { существенных } \\
\text { ограничений } \\
\text { при отсутствии } \\
\text { значительных } \\
\text { опасений }\end{array}$ \\
\hline $18-34$ & 39 & 14 & 29 & 18 \\
\hline $35-54$ & 34 & 13 & 32 & 21 \\
\hline 55 и старше & 34 & 13 & 35 & 18 \\
\hline В целом & 36 & 13 & 32 & 19 \\
\hline
\end{tabular}

Таблица 3. Типология ограничительного поведения с учетом остроты восприятия угрозы, по образовательным группам (\% по строке)

\begin{tabular}{|c|c|c|c|c|}
\hline \multirow[b]{2}{*}{$\begin{array}{c}\text { Образовательные } \\
\text { группы }\end{array}$} & \multicolumn{4}{|c|}{ Типы поведения } \\
\hline & $\begin{array}{c}\text { Существенные } \\
\text { ограничения } \\
\text { при } \\
\text { значительных } \\
\text { опасениях }\end{array}$ & $\begin{array}{c}\text { Отсутствие } \\
\text { существенных } \\
\text { ограничений } \\
\text { при } \\
\text { значительных } \\
\text { опасениях } \\
\end{array}$ & $\begin{array}{c}\text { Существенные } \\
\text { ограничения } \\
\text { при отсутствии } \\
\text { значительных } \\
\text { опасений }\end{array}$ & $\begin{array}{c}\text { Отсутствие } \\
\text { существенных } \\
\text { ограничений } \\
\text { при отсутствии } \\
\text { значительных } \\
\text { опасений }\end{array}$ \\
\hline Высшее образование & 46 & 14 & 27 & 13 \\
\hline $\begin{array}{l}\text { Среднее (начальное) } \\
\text { профессиональное } \\
\text { образование }\end{array}$ & 29 & 14 & 32 & 25 \\
\hline $\begin{array}{l}\text { Без профессионального } \\
\text { образования }\end{array}$ & 25 & 10 & 41 & 24 \\
\hline В целом & 36 & 13 & 32 & 19 \\
\hline
\end{tabular}

Население негативно воспринимает не только эпидемиологический, но и макроэкономический контекст. Лишь около 20 \% опрошенных сочли его благоприятным. При $6 \%$ затруднившихся с ответом почти $74 \%$ респондентов охарактеризовали экономическую ситуацию в стране как скорее плохую или плохую, при этом доля однозначно негативных оценок составила $41 \%$. Такая ситуация неизбежно актуализирует в восприятии населения риски социально-экономического неблагополучия и предполагает поиск возможностей микширования этих рисков, что будет подробно рассмотрено нами далее.

\section{Риски снижения доходов и уровня жизни}

К концу 2019 г., как показывают данные Мониторинга социального самочувствия ${ }^{2}$, россиянами были сформированы достаточно оптимистичные ожидания

\footnotetext{
2 Мониторинг социального самочувствия проводился Институтом социального анализа и прогнозирования РАНХиГС в период 2015-2019 гг. по репрезентативной для взрослого населения России сопоставимой выборке методом личного анкетного интервью. Реализовано 38 волн опроса; объем выборочной совокупности - 1600 респондентов в каждой волне. Подробнее см.: URL: https://www.ranepa.ru/social/informatsionno-analiticheskij-byulleten (дата обращения: 16.12.2020).
} 
относительно перспективной динамики собственной материальной обеспеченности. Так, при $11 \%$ затруднившихся с ответом, $24 \%$ опрошенных предполагали улучшение своего материального положения на горизонте предстоящего года, $53 \%$ ожидали стабильности, и лишь $12 \%$ декларировали предполагаемое снижение уровня жизни. Кризисная реальность первой половины 2020 г. внесла существенные коррективы в реализацию этих планов.

Снижение уровня материальной обеспеченности в период эпидемиологической нестабильности и связанных с этим ограничений оказалось значительным и массовым. Лишь $6 \%$ респондентов заявили, что в течение нескольких месяцев, предшествующих опросу, уровень их благосостояния вырос. Более $43 \%$ опрошенных зафиксировали сокращение своих доходов, в том числе $20 \%$ - существенное.

Ухудшение материального положения в несколько большей степени ощутили представители средневозрастной когорты (см. табл. 4). Как можно предположить, для части молодых людей оказалось возможным оперативно включиться в сегменты рынка труда, минимально пострадавшие в кризисной обстановке или даже получившие в сложившихся условиях потенциал развития. Среди старших возрастов максимальна доля тех, кто свидетельствует о неизменности материального статуса. При этом важно отметить, что в составе каждой из возрастных когорт негативную динамику материального положения отметили более трети опрошенных.

Таблица 4. Динамика материального положения, по возрастным группам (\% по строке)

\begin{tabular}{|l|c|c|c|c|}
\hline \multirow{2}{*}{ Возрастные группы, лет } & \multicolumn{4}{|c|}{ Динамика материального положения } \\
\cline { 2 - 5 } & Улучшилось & $\begin{array}{c}\text { Не } \\
\text { изменилось }\end{array}$ & $\begin{array}{c}\text { Незначительно } \\
\text { ухудшилось }\end{array}$ & $\begin{array}{c}\text { Существенно } \\
\text { ухудшилось }\end{array}$ \\
\hline $18-34$ & 8 & 49 & 24 & 19 \\
\hline $35-54$ & 5 & 48 & 24 & 23 \\
\hline 55 и старше & 3 & 60 & 21 & 16 \\
\hline В целом & 6 & 51 & 23 & 20 \\
\hline
\end{tabular}

Выявлены существенные различия, характеризующие представителей различных доходных групп (см. табл. 5). Наибольшие потери понесли респонденты, имеющие материальный статус ниже среднего и низкий, среди последних существенное ухудшение финансового положения отметила половина опрошенных.

Таблица 5. Динамика материального положения, по группам материальной обеспеченности (\% по строке)

\begin{tabular}{|l|c|c|c|c|}
\hline \multirow{2}{*}{$\begin{array}{c}\text { Уровень материальной } \\
\text { обеспеченности }\end{array}$} & \multicolumn{4}{|c|}{ Динамика материального положения } \\
\cline { 2 - 5 } & Улучшилось & $\begin{array}{c}\text { Не } \\
\text { изменилось }\end{array}$ & $\begin{array}{c}\text { Незначительно } \\
\text { ухудшилось }\end{array}$ & $\begin{array}{c}\text { Существенно } \\
\text { ухудшилось }\end{array}$ \\
\hline Выше среднего & 20 & 64 & 14 & 2 \\
\hline Средний & 6 & 65 & 22 & 7 \\
\hline Ниже среднего & 3 & 44 & 30 & 23 \\
\hline Низкий & 3 & 27 & 20 & 50 \\
\hline В целом & 6 & 51 & 23 & 20 \\
\hline
\end{tabular}


Рассмотрим риски, которым оказались подвержены россияне в сфере занятости.

Заметное сокращение заработной платы или предпринимательского дохода за прошедшие с начала эпидемии месяцы отметили $24 \%$ опрошенных. При этом показательна существенная отраслевая дифференциация, характеризующая уровень снижения доходных поступлений. В наиболее благополучном положении оказались работники государственных сфер-правоохранительной и управленческой, в которых лишь около $6 \%$ отмечают снижение уровня оплаты труда. Группа отраслей, в которую входят социальная сфера, сельское хозяйство, информационные технологии, финансы, промышленность и электроэнергетика, обеспечили среднюю стабильность: более 80 \% занятых сохранили доход в полном объеме. Сотрудники транспортной, строительной и досуговой отраслей пострадали в существенной степени, поскольку около 30 \% занятых не смогли сохранить установленную оплату труда. Максимальными оказались потери для занятых в торговле, бытовом обслуживании, общественном питании и гостиничном бизнесе, где доля утративших как минимум часть дохода составила $38 \%$.

Анализ актуализации иных рисков в сфере занятости показывает, что с сокращением оплачиваемого рабочего времени столкнулись около $16 \%$ наемных работников, а с увеличением трудовой нагрузки, не подкрепленной соответствующей финансовой мотивацией,- $14 \%$. Задержки оплаты труда и вынужденный уход в неоплачиваемый отпуск несколько менее распространены и характеризуют трудовые позиции, соответственно, $11 \%$ и 8\% респондентов.

Данные, приведенные в таблице 6, показывают, что каждый четвертый из работающих опасается потери занятости в текущем году. Массовые представления о соответствующих рисках свойственны самым разным социально-демографическим группам, что иллюстрирует сложившуюся "кризисную социальную норму". В несколько лучшей ситуации находятся представители молодых и средних возрастных когорт, а также работники, имеющие высшее образование, однако межгрупповые различия крайне невелики.

Таблица 6. Субъективная оценка перспектив потери занятости, по возрастным и образовательным группам (\% от работающих, по строке)

\begin{tabular}{|l|c|c|c|}
\hline \multirow{2}{*}{ Социальные группы } & \multicolumn{3}{|c|}{ Оценка перспектив потери занятости } \\
\cline { 2 - 4 } & $\begin{array}{c}\text { Скорее могут } \\
\text { потерять }\end{array}$ & $\begin{array}{c}\text { Скорее не могут } \\
\text { потерять }\end{array}$ & $\begin{array}{c}\text { Затруднились } \\
\text { ответить }\end{array}$ \\
\hline По возрасту & \multicolumn{3}{|c|}{} \\
\hline 18-34 лет & 23 & 70 & 7 \\
\hline $35-54$ лет & 24 & 65 & 9 \\
\hline 55 лет и старше & 30 & 61 & 8 \\
\hline По уровню образования & \multicolumn{3}{|l}{} \\
\hline Высшее образование & 24 & 68 & 11 \\
\hline $\begin{array}{l}\text { Преднее (начальное) } \\
\text { профессиональное } \\
\text { образование }\end{array}$ & 25 & 64 & 9 \\
\hline $\begin{array}{l}\text { Без профессионального } \\
\text { образования }\end{array}$ & 27 & 64 & 9 \\
\hline Вцелом & 25 & 66 & \\
\hline
\end{tabular}


Рассматривая опасения наемных работников относительно возможного ухудшения ситуации в сфере занятости, не связанные с потерей работы, надо отметить, что снижения оплаты труда ожидают $15 \%$ респондентов, а направления в неоплачиваемый отпуск - 24\%. Наиболее распространенные (и практически одинаково значимые) опасения: сокращение оплачиваемого рабочего времени (31\%), задержки зарплатных выплат (31\%) и увеличение трудовой нагрузки без соответствующего повышения оплаты (29\%).

Говоря о краткосрочных перспективах посткризисного развития, население явно склоняется в сторону негативных ожиданий. Безусловно, респонденты надеются на сглаживание кризисной ситуации и преодоление «эпидемиологического шока", поэтому представления о будущем нельзя назвать катастрофичными, но при этом позитивную динамику собственного благосостояния ожидают $15 \%$, а негативную - почти 29 \% опрошенных.

Женщины воспринимают открывающиеся перспективы несколько более критично, но различия по гендерным группам незначительны и составляют лишь несколько процентов. Также крайне невелика дифференциация ожиданий жителей различных поселенческих типов. Определяющим выступает возраст респондентов: представители молодежной когорты отличаются явно бо́льшим оптимизмом (см. табл. 7).

Таблица 7. Представления о перспективной динамике материальной обеспеченности, по социально-демографическим группам (\% по строке)

\begin{tabular}{|c|c|c|c|c|}
\hline \multirow{2}{*}{$\begin{array}{c}\text { Социально-демографические } \\
\text { группы }\end{array}$} & \multicolumn{4}{|c|}{$\begin{array}{c}\text { Представления о перспективной динамике } \\
\text { материальной обеспеченности }\end{array}$} \\
\hline & Улучшится & $\begin{array}{c}\text { Не } \\
\text { изменится }\end{array}$ & Ухудшится & $\begin{array}{c}\text { Затруднились } \\
\text { ответить }\end{array}$ \\
\hline \multicolumn{5}{|l|}{ По гендерной принадлежности } \\
\hline Мужчины & 17 & 46 & 28 & 9 \\
\hline Женщины & 14 & 46 & 30 & 10 \\
\hline \multicolumn{5}{|l|}{ По возрасту } \\
\hline 18-34 лет & 21 & 47 & 23 & 9 \\
\hline 35-54 лет & 14 & 42 & 32 & 12 \\
\hline 55 лет и старше & 9 & 51 & 32 & 8 \\
\hline \multicolumn{5}{|l|}{ По типу поселений } \\
\hline Города более 1 млн жителей & 16 & 40 & 35 & 9 \\
\hline Города более 100 тыс. жителей & 14 & 48 & 30 & 8 \\
\hline Города до 100 тыс. жителей & 15 & 47 & 27 & 11 \\
\hline Сельские поселения & 17 & 50 & 23 & 10 \\
\hline В целом & 15 & 46 & 29 & 10 \\
\hline
\end{tabular}

\section{Адаптационное поведение}

Нарастание эпидемиологической угрозы и введенные в этой связи ограничения поставили население перед необходимостью реализации ситуативных адаптационных практик. Как мы рассматривали выше, большинство респондентов в той или иной степени соблюдало меры, направленные против распространения COVID-19, наиболее массовыми из которых были самоограничение на выход из дома (76 \%) 
и использование средств индивидуальной защиты (72\%). Социальной дистанции старались придерживаться $62 \%$ населения. Каждый третий из опрошенных создал запасы продуктов питания и непродовольственных товаров. Примерно равные группы, составляющие, соответственно, $12 \%$ и $10 \%$, осуществили временный переезд (как правило, в загородный дом) и активизировали доставку продуктов и других необходимых для себя товаров на дом.

Стратегические решения в сложившейся ситуации объективно затруднены значительным уровнем неопределенности. Однако неблагоприятные ожидания в отношении ближайших перспектив развития экономической ситуации предполагают адаптационные усилия, которые могут применяться различными группами населения для достижения приемлемого уровня благосостояния. На горизонте ближайшего года 42 \% опрошенных планируют сокращение потребительской активности, 32\% предполагают найти работу или приработки, 28\% считают для себя возможным и необходимым более активно задействовать возможности личного подсобного хозяйства (ЛПХ), а каждый десятый респондент декларирует планы повышения квалификации за счет получения образования или профессиональной переподготовки (см. табл. 8).

Рассмотрим социально-демографические факторы принятия соответствующих адаптационных решений.

Необходимость экономии актуализирована в первую очередь женщинами. Также сокращение потребительских расходов в большей степени ожидается со стороны городских жителей и обладателей высшего образования, то есть представителей социальных групп, имеющих более сложную структуру потребления.

Активизация усилий на рынке труда, выражающаяся в поиске постоянной работы или приработков, ожидаемо является стратегией сравнительно молодых когорт. Развитые рынки труда крупных и средних городов позволяют их жителям рассчитывать на успешный поиск работы и приработков, но различия по типам поселений в данном случае невелики и составляют около 4-5\%. Респонденты, получившие профессиональное образование (вне зависимости от его уровня), чаще рассчитывают на удержание имеющихся рабочих мест, в отличие от тех, кто не имеет диплома и предполагает необходимость большей мобильности на нестабильном рынке труда.

Повышение образовательного и квалификационного потенциала, по понятным причинам, массово востребовано молодежью, и каждый пятый из опрошенных до 35 лет видит в этом возможность эффективного приспособления к социально-экономическим реалиям. Важно отметить, что такие возможности актуализируются и значительной частью представителей среднего возраста. В несколько большей степени задумываются о получении необходимого образования те, кто имеет вузовский диплом, проживая в крупных и средних городах.

Максимизация возможностей личного подсобного хозяйства очевидно приоритетна для жителей сельской местности, но такая адаптационная практика востребована и горожанами, в том числе и $17 \%$ населения мегаполисов. Надежды на использование ЛПХ (личного подсобного хозяйства) увеличиваются с возрастом, когда шансы эффективного использования иных стратегий снижаются, и в большей степени свойственны женщинам. 
Таблица 8. Планируемые адаптационные практики, по социально-демографическим группам (\% по строке, допускалось более одного ответа)

\begin{tabular}{|c|c|c|c|c|}
\hline \multirow[b]{2}{*}{$\begin{array}{c}\text { Социально-демографические } \\
\text { группы }\end{array}$} & \multicolumn{4}{|c|}{ Планируемые адаптационные практики } \\
\hline & Экономия & $\begin{array}{c}\text { Поиск } \\
\text { работы/ } \\
\text { приработков }\end{array}$ & $\begin{array}{c}\text { Получение } \\
\text { образования }\end{array}$ & $\begin{array}{c}\text { Активизация } \\
\text { лпХ }\end{array}$ \\
\hline \multicolumn{5}{|l|}{ По гендерной принадлежности } \\
\hline Мужчины & 37 & 34 & 12 & 24 \\
\hline Женщины & 47 & 30 & 9 & 33 \\
\hline \multicolumn{5}{|l|}{ По возрасту } \\
\hline 18-34 года & 42 & 37 & 19 & 19 \\
\hline 35-54 года & 43 & 33 & 8 & 28 \\
\hline 55 лет и старше & 41 & 21 & 2 & 43 \\
\hline \multicolumn{5}{|l|}{ По уровню образования } \\
\hline Высшее образование & 47 & 30 & 13 & 25 \\
\hline $\begin{array}{l}\text { Среднее (начальное) } \\
\text { профессиональное образование }\end{array}$ & 39 & 30 & 8 & 32 \\
\hline $\begin{array}{l}\text { Без профессионального } \\
\text { образования }\end{array}$ & 39 & 40 & 10 & 27 \\
\hline \multicolumn{5}{|l|}{ По типу поселений } \\
\hline Города более 1 млн жителей & 46 & 33 & 13 & 17 \\
\hline Города более 100 тыс. жителей & 43 & 34 & 12 & 22 \\
\hline Города до 100 тыс. жителей & 45 & 29 & 8 & 28 \\
\hline Сельские поселения & 35 & 29 & 8 & 49 \\
\hline В целом & 42 & 32 & 10 & 28 \\
\hline
\end{tabular}

Как мы видим, значительные группы россиян предполагают возможность достаточно длительного периода экономической нестабильности и декларируют готовность к реализации разнообразных адаптационных практик.

\section{Оценка управленческих решений и ожидания социальной поддержки}

На фоне усугубления эпидемиологической обстановки в конце первого квартала 2020 г. государственными органами власти был принят ряд управленческих решений, накладывающих ограничения как на жизнедеятельность частных лиц, так и на ведение предпринимательской деятельности. В оценке введенных мер мнения населения разделились. Половина опрошенных считает, что предпринимаемые действия абсолютно адекватны ситуации. Распределение вариантов ответов между группами населения, которые не вполне удовлетворены реализуемым комплексом мер, говорит о том, что общественные ожидания явно направлены в сторону большей ответственности государства за поддержание эпидемиологической и социально-экономической стабильности: при 5 \% затруднившихся с ответом, $11 \%$ респондентов считают предпринятые меры чрезмерными, а $33 \%$ - недостаточными. 
Комплекс реализованных управленческих решений чаще называют достаточным женщины, представители старших возрастов и те, кто имеет средний уровень доходов. Среди выражающих мнение о недостаточности предпринятых действий выделяются самые молодые из респондентов и имеющие высокий уровень материальной обеспеченности. Мнение о чрезмерности ограничительных мер наиболее представлено среди мужчин, а также представителей малообеспеченных слоев, которые, не имея финансовых резервов, столкнулись с наибольшими сложностями на изменившемся рынке труда.

В ходе исследования нами был также выявлен спектр мнений, характеризующий восприятие административных усилий, направленных на социальную поддержку населения в условиях эпидемиологического шока. Выяснилось, что лишь каждый пятый из опрошенных считает адекватными действия, предпринятые государственными органами в этом направлении. Большинство респондентов полагает, что такие меры либо недостаточны, либо вовсе отсутствуют-распространенность этих оценок составила около $40 \%$ и 31 \% соответственно, а $9 \%$ затруднились с ответом. Важно подчеркнуть, что отмеченный спектр мнений достаточно равномерно распределен среди представителей всех социально-демографических групп. Единственным значимо влияющим фактором, по понятным причинам, является финансовый: в каждой нижестоящей группе материального статуса доля удовлетворенных реализованным комплексом социальной поддержки существенно снижается.

При этом запрос на социальную помощь в кризисной ситуации, с учетом неясных перспектив ее стабилизации, ощутимо велик: нуждающимися в ней назвали себя $62 \%$ опрошенных, в том числе $16 \%$ зафиксировали критичный уровень потребности в помощи (см. табл. 9). Наиболее настоятельный запрос отмечается со стороны групп населения, находящихся в ситуации ресурсного дефицита - как при низком уровне индивидуального образовательного потенциала, так и в условиях неразвитого рынка труда сельских поселений. Представители старшей возрастной когорты реже прочих высказывают острую нуждаемость в социальной поддержке, что можно объяснить заниженным уровнем ожиданий на основе накопленного начиная с 1990-х годов опыта преодоления социально-экономических кризисов.

Таблица 9. Острота запроса на социальную поддержку, по социально-демографическим группам (\% по строке)

\begin{tabular}{|c|c|c|c|c|}
\hline \multirow{2}{*}{$\begin{array}{c}\text { Социально-демографические } \\
\text { группы }\end{array}$} & \multicolumn{4}{|c|}{$\begin{array}{c}\text { Самооценка нуждаемости } \\
\text { в помощи со стороны государства }\end{array}$} \\
\hline & $\begin{array}{c}\text { Остро } \\
\text { нуждаются }\end{array}$ & $\begin{array}{c}\text { Скорее } \\
\text { нуждаются }\end{array}$ & $\begin{array}{c}\text { Скорее } \\
\text { не нуждаются }\end{array}$ & $\begin{array}{c}\text { Не } \\
\text { нуждаются }\end{array}$ \\
\hline \multicolumn{5}{|l|}{ По гендерной принадлежности } \\
\hline Мужчины & 15 & 43 & 30 & 12 \\
\hline Женщины & 18 & 49 & 26 & 7 \\
\hline \multicolumn{5}{|l|}{ По возрасту } \\
\hline 18-34 года & 16 & 48 & 27 & 9 \\
\hline 35-54 года & 18 & 45 & 28 & 9 \\
\hline 55 лет и старше & 14 & 46 & 29 & 11 \\
\hline
\end{tabular}




\begin{tabular}{|l|c|c|c|c|}
\hline \multirow{2}{*}{$\begin{array}{c}\text { Социально-демографические } \\
\text { группы }\end{array}$} & \multicolumn{4}{|c|}{$\begin{array}{c}\text { Самооценка нуждаемости } \\
\text { вомощи со стороны государства }\end{array}$} \\
\cline { 2 - 5 } & $\begin{array}{c}\text { Остро } \\
\text { нуждаются }\end{array}$ & $\begin{array}{c}\text { Скорее } \\
\text { нуждаются }\end{array}$ & $\begin{array}{c}\text { Скорее } \\
\text { не нуждаются }\end{array}$ & $\begin{array}{c}\text { Hе } \\
\text { нуждаются }\end{array}$ \\
\hline По уровню образования & 10 & 44 & 34 & 12 \\
\hline Высшее образование & 19 & 50 & 24 & 7 \\
\hline $\begin{array}{l}\text { Среднее (начальное) } \\
\text { профессиональное образование }\end{array}$ & 25 & 46 & 22 & 7 \\
\hline $\begin{array}{l}\text { Без профессионального } \\
\text { образования }\end{array}$ & \multicolumn{5}{|c|}{} \\
\hline По типу поселений & 15 & 42 & 32 & 11 \\
\hline Города более 1 млн жителей & 14 & 46 & 29 & 11 \\
\hline Города более 100 тыс. Жителей & 16 & 48 & 27 & 9 \\
\hline Города до 100 тыс. Жителей & 21 & 50 & 23 & 6 \\
\hline Сельские поселения & \multicolumn{5}{|c|}{} \\
\hline По материальному статусу & 4 & 17 & 45 & 34 \\
\hline Выше среднего & 5 & 44 & 39 & 12 \\
\hline Средний & 14 & 60 & 22 & 4 \\
\hline Ниже среднего & 47 & 44 & 7 & 2 \\
\hline Низкий & 16 & 46 & 28 & 10 \\
\hline В целом & \multicolumn{5}{|c|}{} \\
\hline
\end{tabular}

Представители наименее обеспеченных слоев населения ожидаемо максимизируют запрос на социальную поддержку. Именно им реализуемые формы и объемы помощи со стороны государства реже всего представляются сообразными и достаточными.

\section{Заключение}

Как показывают результаты исследования, около половины опрошенных считают угрозы, связанные с неблагоприятной эпидемиологической обстановкой, в той или иной степени серьезными, и чем крупнее населенный пункт, тем более актуализированы соответствующие опасения. На фоне достаточно высокого доверия к административно предпринимаемым мерам (51\% респондентов считают реализованные в регионах их проживания меры, ограничивающие социальные взаимодействия и экономическую активность, адекватными сложившейся ситуации), россияне в своем большинстве ответственно отнеслись к необходимости соблюдений социального дистанцирования и режима самоизоляции, а также использования средств индивидуальной защиты.

Ограничения, вызванные распространением новой коронавирусной инфекции, повлияли как на социальные взаимодействия, так и на экономическую активность россиян. Около $24 \%$ работающих респондентов отметили уменьшение оплаты труда за время, прошедшее с начала пандемии и введения связанных с ней ограничений, в том числе $14 \%$ потеряли не менее четверти имевшегося дохода. Больше всего пострадали работающие в торговле, сферах бытового обслуживания и общественного питания, а также в гостиничном бизнесе. Каждый четвертый занятый в экономике респондент опасается потери работы или собственного 
бизнеса в текущем году. Около 30 \% (в отношении каждой из перечисленных далее ситуаций) предполагают вероятность сокращения оплачиваемого рабочего времени, задержек выплаты заработной платы и неоплачиваемого увеличения трудовой нагрузки. Риски существенного снижения оплаты труда актуальны для $15 \%$ респондентов.

В ответ на негативные изменения социально-экономического контекста население актуализирует адаптационные стратегии, главной из которых является потребительская экономия (к ней планируют прибегнуть $42 \%$ опрошенных). Трудовые стратегии - поиск альтернативной работы или приработков - планирует реализовать каждый третий россиянин. Традиционной и достаточно массовой формой адаптации выступает также использование приусадебных участков для выращивания необходимых продуктов.

Если в отношении ситуационных мер противодействия эпидемиологической угрозе население скорее склонно солидаризироваться с административными усилиями органов исполнительной власти, признавая адекватность принимаемых решений, то в оценке масштабов социальной поддержки очевидны расхождения. Более $43 \%$ респондентов зафиксировали сокращение объема располагаемых доходов за последнее время, в том числе 20 \% отметили их существенное сокращение. При этом почти 30 \% опрошенных предполагают, что не смогут преодолеть последствия кризисной ситуации без существенного снижения уровня жизни. Запрос на поддержку со стороны государства в этих условиях достаточно высок, а предпринимаемые меры массово оцениваются населением как недостаточные.

\section{Список литературы (References)}

Авраамова Е. М., Логинов Д. М. Адаптационные ресурсы населения: попытка количественной оценки // Мониторинг общественного мнения: экономические и социальные перемены. 2002. № 3. С. 13-17.

Avraamova E. M., Loginov D. M. (2002) Adaptive Resources of the Population: An Attempt to Quantify. Monitoring of Public Opinion: Economic and Social Changes. No. 3. P. 13-17. (In Russ.)

Авраамова Е. М., Логинов Д. М. Социальное самочувствие: население чувствует кризис все больше, а видит-все меньше // Экономическое развитие России. 2015. T. 22. № 6. C. 79-82. URL: http://www.edrussia.ru/archive/2015/237-06-2015 (дата обращения 23.12.2020).

Avraamova E. M., Loginov D. M. (2015) Social Well-Being: The Population Feels the Crisis More, but Sees Less. Russian Economic Development. Vol. 22. No. 6. P. 79-82. URL: http:/ /www.edrussia.ru/archive/2015/237-06-2015 (accessed: 22.12.2020). (In Russ.)

Аналитический бюллетень НИУ ВШЭ об экономических и социальных последствиях коронавируса в России и в мире/Высшая школа экономики. № 2. 21.05.2020. URL: https://www.hse.ru/mirror/pubs/share/366627594.pdf (дата обращения 23.12.2020). 
National Research University Higher School of Economics. HSE Analytical Bulletin on the Economic and Social Consequences of Coronavirus in Russia and in the World. No. 2. 21.05.2020. https://www.hse.ru/mirror/pubs/share/366627594. pdf (accessed: 22.12.2020). (In Russ.)

Анпилов С. М., Сорочайкин А.Н. Россия в постпандемийном мире // Основы экономики, управления и права. 2020. № 2. C. 24-30. URL: https://0eb752d5-456f-43f1-880c1aaca28824fe.filesusr.com/ugd/5520ef_5bdf86e62e8b4ddab45d675db1bff105. pdf (дата обращения: 22.12.2020).

Anpilov S. M., Sorochaikin A. N. (2020) Russia in the Post-Pandemic World. Economy, Governance and Law Basis. No. 2. P. 24-30. URL: https://0eb752d5-456f-43f1-880c1aaca28824fe.filesusr.com/ugd/5520ef_5bdf86e62e8b4ddab45d675db1bff105. pdf (accessed: 22.12.2020). (In Russ.)

Григорьев Л. М., Павлюшина В. А., Музыченко Е. Э. Падение в мировую рецессию 2020... // Вопросы экономики. 2020. № 5. С. 5-24. https://doi.org/10.32609/ 0042-8736-2020-5-5-24.

Grigoryev L. M., Pavlyushina V. A., Muzychenko E. E. (2020) The Fall into 2020 Recession... Voprosy Ekonomiki. No. 5. P. 5-24. (In Russ.) https://doi.org/10.3260 9/0042-8736-2020-5-5-24.

Гордон Л. А. Социальная адаптация в современных условиях // Социологические исследования. 1994. № 8-9. С. 3-15. URL: http://ecsocman.hse.ru/socis/ msg/16698157.html (дата обращения: 22.12.2020).

Gordon L. A. (1994) Social Adaptation in the Modern Conditions. Sociological Studies. No. 8-9. P. 3-15. URL: http://ecsocman.hse.ru/socis/msg/16698157.html (accessed: 22.12.2020). (In Russ.)

Заславская Т.И. Социальный механизм трансформации российского общества // Социологический журнал. 1995. № 3. С. 5-21. URL: https://www.isras.ru/index. php?page_id=2384\&id=183\&l=\&j=1 (дата обращения: 23.12 .2020 ).

Zaslavskaya T. I. (1995) The Social Mechanism for the Russian Society Transformation. Sociological Journal. No. 3. P. 5-21. URL: https://www.isras.ru/index.php?page_ $i d=2384 \& i d=183 \& \mid=\& j=1$ (accessed: 23.12 .2020$)$. (In Russ.)

Колодко Г.В. Последствия. Экономика и политика в постпандемическом мире. // Вопросы экономики. 2020. № 5. С. 25-44. https://doi.org/10.32609/0042-87 36-2020-5-25-44.

Kolodko G. W. (2020) After. Economics and Politics of the Post-Pandemic World. Voprosy Ekonomiki. No. 5. P. 25-44. (In Russ.) https://doi.org/10.32609/0042-8 736-2020-5-25-44.

Мониторинг мнений (ВЦИОМ): март - апрель 2020 // Мониторинг общественного мнения: экономические и социальные перемены. 2020а. № 2. С. 293-311. URL: https://www.monitoringjournal.ru/index.php/monitoring/article/view/1639 (дата обращения: 23.12.2020). 
Public Opinion Poll (VCIOM): March - April 2020 (2020) Monitoring of Public Opinion: Economic and Social Changes. No. 2. P. 293-311. URL: https://www.monitoringjournal.ru/index.php/monitoring/article/view/1639 (accessed: 23.12.2020). (In Russ.)

Мониторинг мнений (ВЦИОМ): май - июнь 2020 // Мониторинг общественного мнения: экономические и социальные перемены. 2020б. № 3. С. 224-246. URL: https://www.monitoringjournal.ru/index.php/monitoring/article/view/1696 (дата обращения: 23.12.2020).

Public Opinion Poll (VCIOM): May - June 2020. (2020) Monitoring of Public Opinion: Economic and Social Changes. No. 3. P. 224-246. URL: https:/ /www.monitoringjournal.ru/index.php/monitoring/article/view/1696 (accessed: 23.12.2020). (In Russ.)

Полбин А. В., Синельников-Мурылев С. Г., Трунин П.В. Экономический кризис 2020 г.: причины и меры по его преодолению и дальнейшему развитию России // Вопросы экономики. 2020. № 6. С. 5-21. https://doi.org/10.32609/0042-8 736-2020-6-5-21.

Polbin A. V., Sinelnikov-Murylev S.G., Trunin P.V. (2020) The Economic Crisis of 2020: Reasons, Policies to Deal With and Further Development of the Russian Economy. Voprosy Ekonomiki. No. 6. P. 5-21. https://doi.org/10.32609/0042-8736-2020-65-21. (In Russ.)

Тихонова Н.Е. Динамика социальной стратификации в постсоветском обществе // Общественные науки и современность. 1997. № 5. C. 5-14. URL: http://ecsocman. hse.ru/ons/msg/18778805.html (дата обращения: 23.12.2020).

Tikhonova N. E. (1997) Dynamics of Social Stratification in the Post-Soviet Society. Social Sciences and Contemporary World. No. 5. P. 5-14. URL: http://ecsocman.hse. ru/ons/msg/18778805.html (accessed: 23.12.2020). (In Russ.)

Тихонова Н.Е., Каравай А.В. Ресурсы россиян в условиях кризиса: динамика и роль в адаптации к новым условиям // Социологические исследования. 2016. № 10. C. 43-53. URL: https://www.isras.ru/index.php?page_id=2624\&jn=socis\&jn=soci s\&jid=6393 (дата обращения: 23.12.2020).

Tikhonova N.E., Karavay A. V. (2016) Russian People Resources in Crisis: Dynamics and Its Role in Adaptation to the New Conditions. Sociological Studies. No. 10. P. 43-53. URL: https://www.isras.ru/index.php?page_id=2624\&jn=socis\&jn=socis\&jid=6393 (accessed: 23.12.2020). (In Russ.)

Щетинина И.В. Государственные ограничительные меры в условиях пандемии и их социально-экономические последствия // Всероссийский экономический журнал «ЭКО». 2020. Т. 50. № 5. С. 156-174. https://doi.org/10.30680/ есо0131-7652-2020-5-156-174.

Shchetinina I.V. (2020) Public Restrictions During Pandemic and Their Socio-Economic Consequences. ECO. Vol. 50. No. 5. P. 156-174. https://doi.org/10.30680/ eco0131-7652-2020-5-156-174. (In Russ.) 